\title{
Bioprotective potential of lactic acid bacteria
}

\author{
É. Laslo ${ }^{1}$ \\ e-mail: lasloeva@uni.sapientia.ro \\ É. György ${ }^{2}$ \\ e-mail: gyorgyeva@uni.sapientia.ro
}

\section{Cs. D. András ${ }^{2}$}

e-mail: andrascsaba@uni.sapientia.ro

${ }^{1}$ Sapientia Hungarian University of Transylvania (Cluj-Napoca, Romania),

Faculty of Economics, Socio-Human Sciences and Engineering, Department of Bioengineering, RO-530104 Miercurea Ciuc, 1 Libertăţii Sq.

${ }^{2}$ Sapientia Hungarian University of Transylvania (Cluj-Napoca, Romania), Faculty of Economics, Socio-Human Sciences and Engineering, Department of Food Science, RO-530104 Miercurea Ciuc, 1 Libertăţii Sq.

\begin{abstract}
Acidification in lactic-fermented foods is realized by lactic acid bacteria as an added starter culture or by autochthonous strains. These microbial strains possess different prominent features that define the technological, organoleptic, nutritional, and microbial safety aspects of the product. The bioprotective effect of the bacterial strains may be related to antagonistic properties against food spoilage and/or pathogenic strains. The aim of the present study is to determine the antimicrobial properties of three different food-grade lactic acid bacteria in order to use them as bioprotective cultures. Our findings show that the Lactobacillus pentosus, Enterococcus faecalis, and Pediococcus parvulus exerted a bacteriostatic effect on Escherichia coli and Bacillus cereus, whereas the Saccharomyces cerevisiae growth was not inhibited, which made them susceptible agent for co-culture systems.
\end{abstract}

Keywords and phrases: lactic acid bacteria, bioprotective, antagonistic 


\section{Introduction}

One of the most common and ancient methods of food preservation is fermentation, and that process is driven by microorganisms. The acidification in fermented foods is caused by the formation of organic acids as primary metabolites, e.g. the lactic acid is synthetized by lactic acid bacteria (LAB) as added starter culture or by autochthonous strains. These bacterial strains possess different prominent features that define the technological, organoleptic properties as well as nutritional and microbial safety aspects of the product (Altieri et al., 2017; Ruiz-Rodríguez et al., 2017). The bioprotective potential of the bacterial strains is related to antagonistic properties. The LAB exert their protective activity mainly via three modes: displacement/exclusion, competition for nutrients, and production of antimicrobial metabolites (Ben Said et al., 2019). The antimicrobial metabolites, however, may act through different mechanisms such as the inhibition of the spoilage microorganisms resulting in the membrane destabilization in spoilage microorganisms, proton gradient interference, enzyme inhibition, or creation of reactive oxygen species (Siedler et al., 2019).

The inhibitory effect of LAB is associated with metabolic compounds like primary metabolic products as different organic acids or complex compounds derived from protein metabolism (Rodríguez et al., 2017). It was shown that lactic acid and acetic acid derived from central carbon metabolism comprise an antimicrobial spectrum, which includes some Gram-positive and some Gramnegative organisms and yeasts. Hydrogen peroxide, acetaldehyde, and acetoin have an antimicrobial spectrum, which includes also Gram-positive and some Gram-negative organisms and yeasts (Siedler et al., 2019). The short-chain fatty acids are the prominent factor in the antagonistic phenomena (Gao et $a l ., 2019)$. Due to the production of acetic acid, the $\mathrm{pH}$ decreases, and the different undesirable microorganisms are deactivated. The other mechanism that may prevail is the weak acid theory, resulting in the acidification of cytoplasm. Additionally, the acids may trigger other disorders in cell such as energy competition, intracellular anion accumulation, and inhibition or induction of the synthesis of different macromolecules. It was shown that acetic acid has an inhibitory effect against Saccharomyces cerevisiae (Gao et al., 2019). Synthetised or hydrolysed proteinaceous compounds are also responsible for antimicrobial activities. The bacteriocins are effective against most spoilage bacteria and foodborne pathogens (Zhang, 2019; Todorov \& Chikindas, 2020). The antifungal peptides derived from the hydrolysis of food proteins show an inhibitory effect against moulds (Siedler et al., 2019). Competitive exclusion 
as a novel antimicrobial mechanism is also associated with fungal growth inhibition. Exhaustion of manganese is an inhibitory effect of LAB against yeast and moulds (Siedler et al., 2020).

LAB possess antimicrobial activity against foodborne pathogens and spoilage yeast (Narbad \& Wang, 2018). The supernatant of LAB liquid cultures and different combinations of LAB effectively inhibited the Escherichia coli serotypes, what may represent a public health concern. This bacterium is involved in the faecal contamination of fermented foods and may cause foodborne diseases (Gao et al., 2019). Another studied microbe was the Bacillus cereus, being a common food-borne pathogen that contaminates plant and dairy products. These bacterial strains are thermoduric spore formers. Toxins produced by these bacteria, such as cereulide, cytotoxin $\mathrm{K}$, haemolysin BL, or nonhemolytic enterotoxin, cause food poisoning (Laslo \& György, 2018). Two types of foodborne diseases are attributed to these bacteria: an emetic intoxication and diarrheal infection (EFSA, 2005). Different probiotic strains exert antibacterial effects on these bacteria (Zhang et al., 2016).

Considering the functional aspects of LAB, these microorganisms may represent a biological alternative to the use of synthetic additives in food. The aim of the present study is to determine the antimicrobial and bacteriostatic properties of food-grade lactic acid bacteria in order to provide evidence for or confirm them as bioprotective cultures to highlight their potential as an alternative to chemical additives.

\section{Materials and methods}

Determination of the antagonistic activity of $L A B$

The antagonistic activity of LAB was analysed through growth curve analysis. We determined the effect of the selected three food-grade LAB on the growth of Escherichia coli, Bacillus cereus, and Saccharomyces cerevisiae and then inoculated them with different inoculum sizes. The three LAB strains were Lactobacillus pentosus and Enterococcus faecalis originated from whey and Pediococcus parvulus originated from sauerkraut juice. The LAB were inoculated in MRS broth and incubated at $37^{\circ} \mathrm{C}$ for $48 \mathrm{hrs}$. The cell-free supernatant was recovered by centrifuge at $14000 \mathrm{rpm}$ for $10 \mathrm{~min}$.

The tested bacterial species, Escherichia coli and Bacillus cereus liquid culture, were grown for $12 \mathrm{hrs}$ at $28^{\circ} \mathrm{C}$ and inoculated in $180 \mu \mathrm{l}$ nutrient broth with $1 \%, 1.5 \%$, and $2 \%$. Also, $50 \mu \mathrm{l}$ of the cell-free supernatant of LAB was added, and the absorbance values at the wavelength of $\lambda=595 \mathrm{~nm}$ were 
recorded by Fluostar Optima Microplate Reader (BMG Labtech, Ortenberg, Germany) in every 15 min for $25 \mathrm{hrs}$.

The tested Saccharomyces cerevisiae liquid culture was grown for $12 \mathrm{hrs}$ at $28^{\circ} \mathrm{C}$ and inoculated in $180 \mu \mathrm{l}$ complex broth with $1 \%, 1.5 \%$, and $2 \%$. Also, 50 $\mu \mathrm{l}$ of the cell-free supernatant of LAB was added, and the absorbance values (at $\lambda=595 \mathrm{~nm}$ ) were recorded by Fluostar Optima Microplate Reader every $15 \mathrm{~min}$ for $25 \mathrm{~h}$. The measurement was repeated five times. The growth curve representation was performed with Statistica 8.0 (StatSoft, Inc., Oklahoma, USA).

\section{$3 \quad$ Results and discussions}

One of the beneficial effects of LAB is related to its antagonistic activity against other microorganisms. The antagonistic effects of the three different food-grade LAB was evaluated during the growth of the tested bacteria inoculated with different concentrations. In the case of E. coli, the used supernatants of the LAB liquid culture exerted a growth inhibition effect. The inoculation percentage affected the growth kinetics.

The LAB supernatant effect on the growth of $E$. coli inoculated with different inoculum concentrations is shown in Fig. 1.

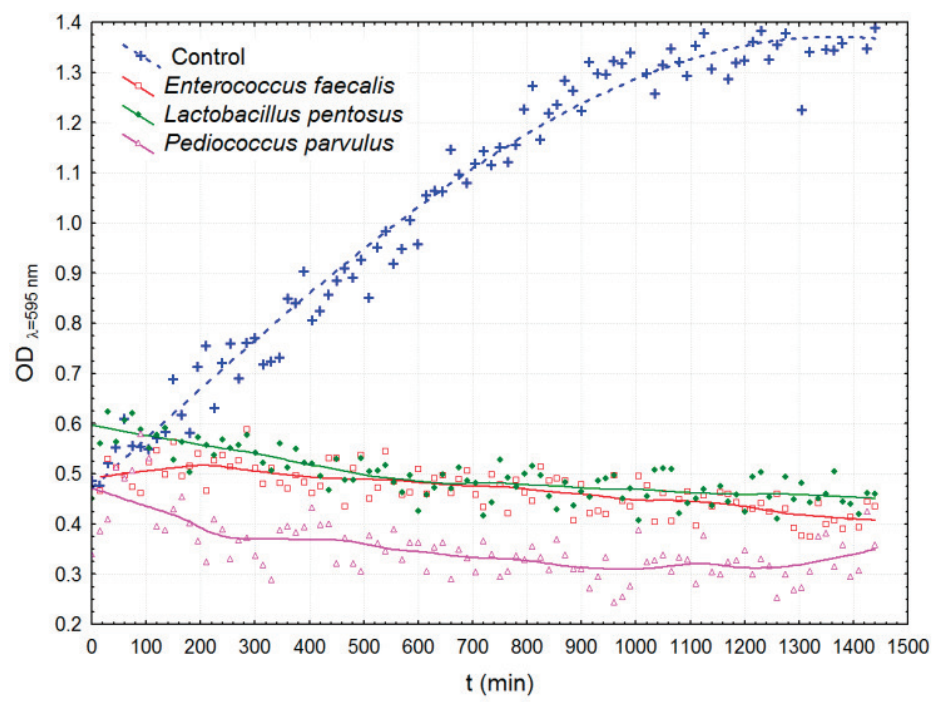

(a) 


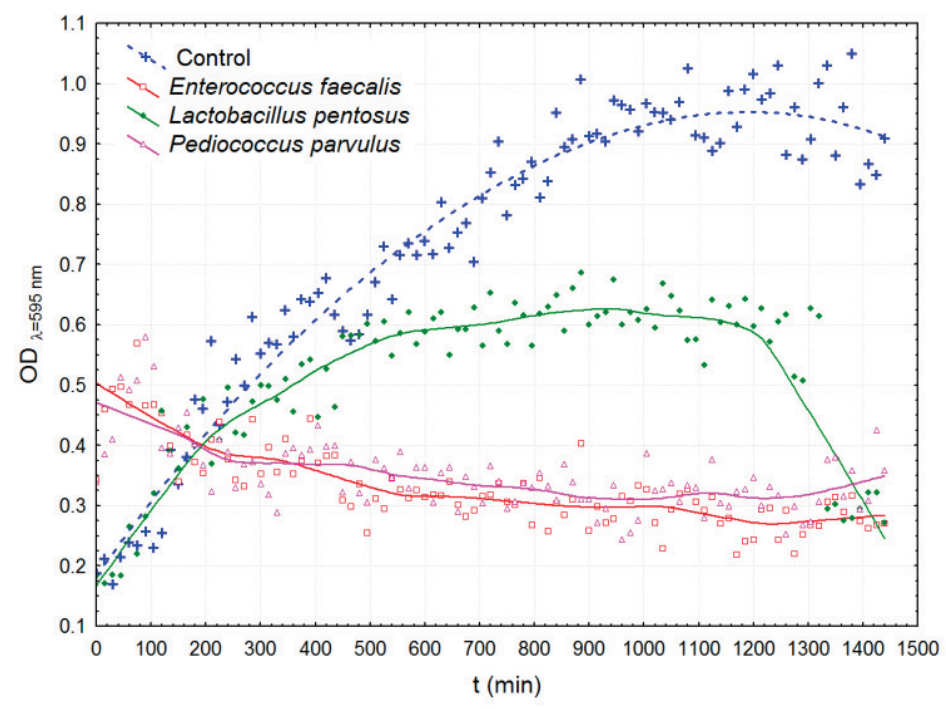

b)

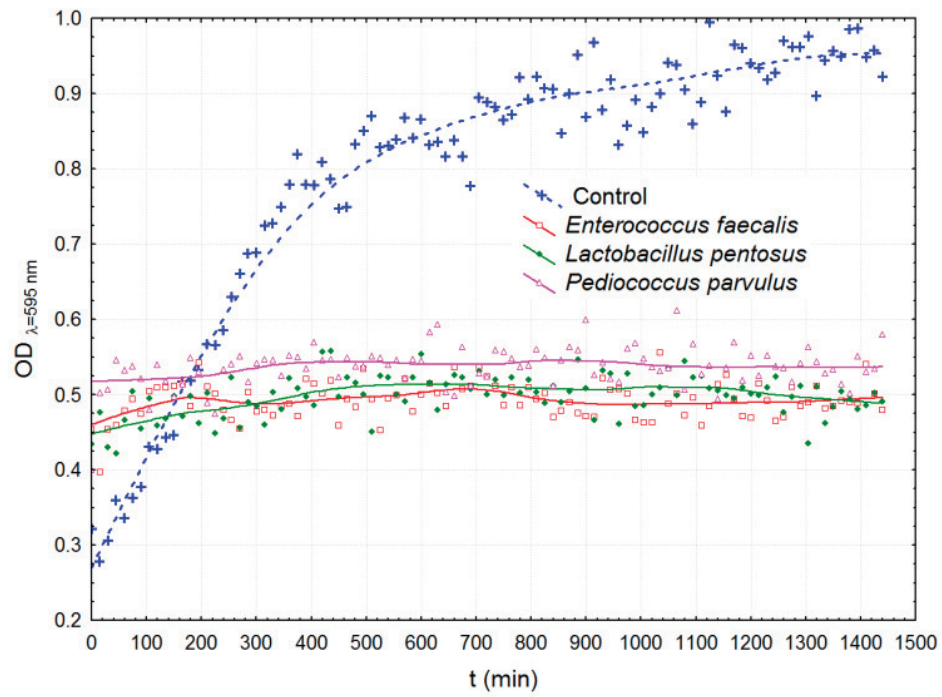

(c)

Figure 1. Growth curves of E. coli $1 \%$ (a), 1.5\% (b), and 2\% (c) in the presence of supernatants of LAB 
In the presence of Pediococcus parvulus, the supernatant of E. coli with $1.5 \%$ inoculum presented a slight growth, but ultimately the death phase appeared. The antibacterial effect was also found against $B$. cereus. The LAB supernatant effect on the growth of $B$. cereus inoculated with $1 \%$ inoculum is shown in Fig. 2.

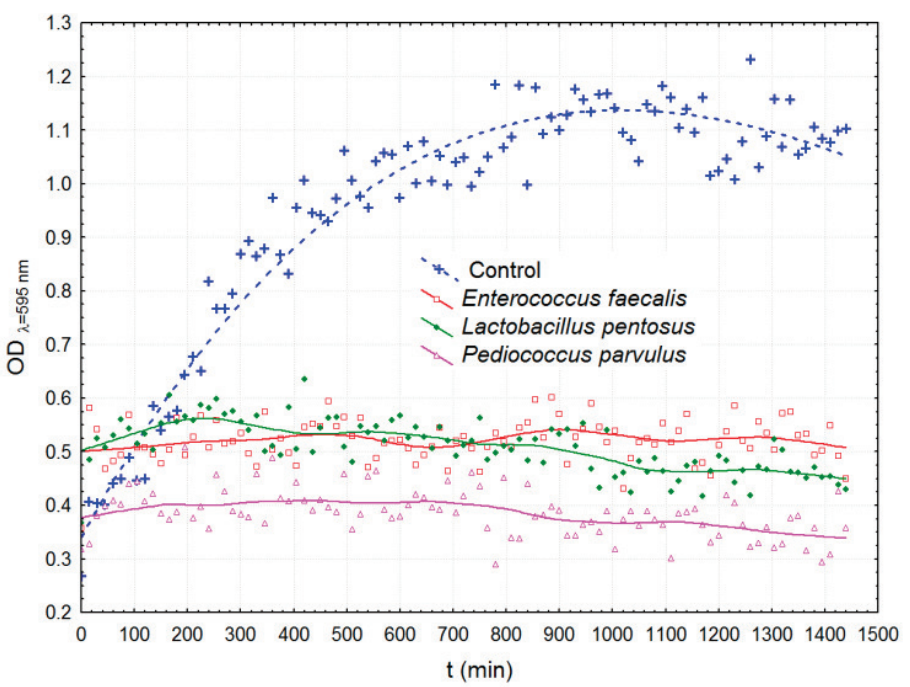

(a)

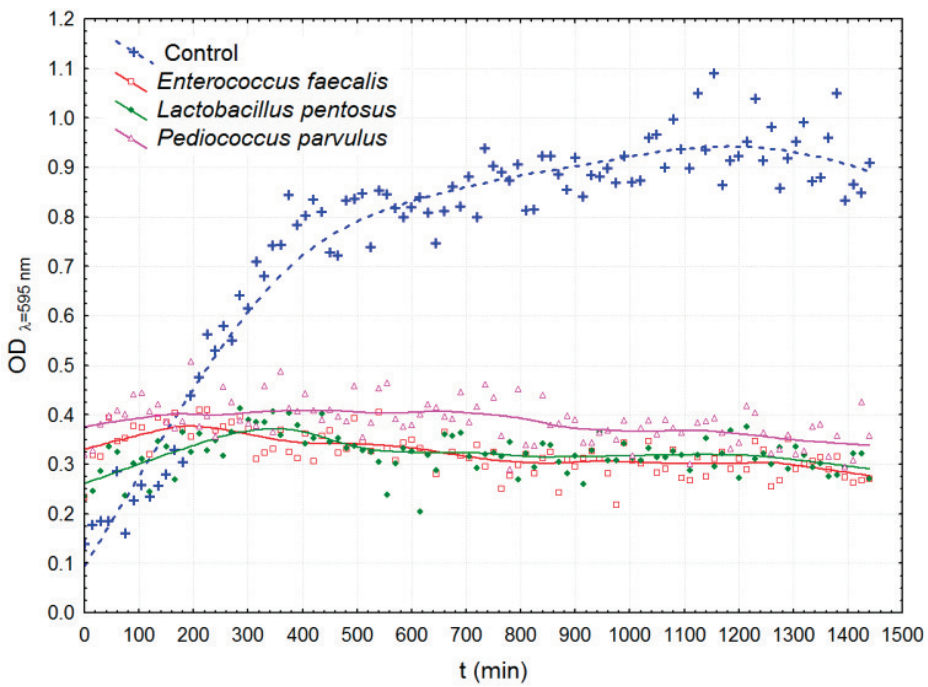

(b) 


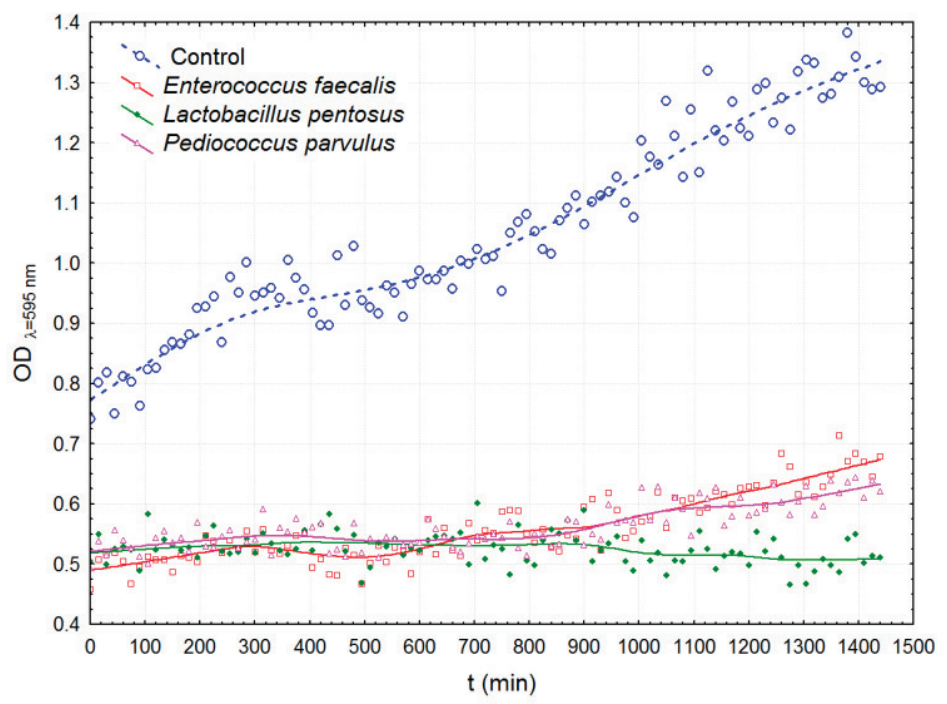

(c)

Figure 2. Growth curves of B. cereus $1 \%$ (a), $1.5 \%$ (b), and $2 \%$ (c) in the presence of supernatants of LAB

Lactobacillus pentosus is involved in vegetable fermentation, such as the case of olive, but it can be also detected in different traditional dairy products. Different strains of these bacteria exhibit probiotic characteristics providing health benefits (Belicová et al., 2013; Montoro et al., 2016).

$Y i$ et al. (2020) found that L. pentosus was an appropriate candidate for the biocontrol of food-borne pathogens such as E. coli. It has been shown that these food-grade bacteria produced antibacterial peptides. L. pentosus $22 \mathrm{C}$ originated from traditional yoghurt with a small peptide pentocin $22 \mathrm{C}$ production capacity, and it exerted antagonistic activity against $B$. cereus (Motahari et al., 2017).

Bacterial strains belonging to genus Enterococcus, such as Enterococcus faecalis, are widespread in nature. This genus comprises pathogenic and beneficial strains too. Some species of Enterococcus faecalis are involved in food preservation, possessing various beneficial traits. It can be found in all types of fermented foods as adjunct starter cultures from vegetables through dairy to meat products. It was shown that these strains are able to produce enterocins, and antimicrobial peptide with an active role in the growth inhibition of foodborne pathogenic and spoilage bacteria (Hanchi et al., 2018; Baccouri et al., 
2019). Due to antimicrobial activity, E. faecalis is proposed as food-grade protective bacteria in dairy industry (Silvetti et al., 2014).

P. parvulus, an obligate homofermentative bacterium, belongs to the Pediococcus genus. These bacteria appear in different fermentation environments, such as wine, brewery, and meat, and plant fermentations such as olive (Wade et al., 2018). Heperkan et al. (2014) proposed P. parvulus (E42) as a potential adjunct culture in traditional fermented beverage making such as boza. Immerstrand et al. (2010) highlighted that $P$. parvulus is a good candidate for a protective culture, and, besides the technological aspects, it exerts an antibacterial effect on $B$. cereus. Apart from the peptides, different organic compounds with antagonistic activity in LAB supernatant were identified (Siedler et al., 2019).

The effect of the LAB supernatants on the growth of yeast is presented in Fig. 3.

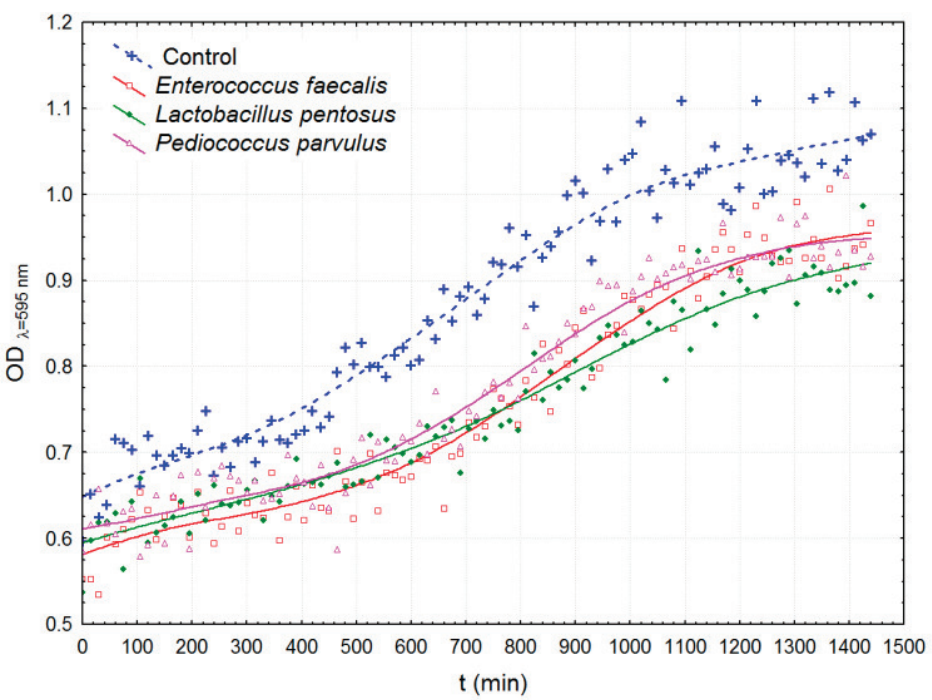

(a)

Our results show that the supernatant of the LAB does not inhibit the growth of the Saccharomyces cerevisiae. In the case of $1.5 \%$ inoculum, the growth was even stimulated (Fig. 3b). A similar result was found in dairy products, where the stimulated growth of Saccharomyces boulardii was observed and its survival was assured (Lourens-Hattingh \& Viljoen, 2001). 


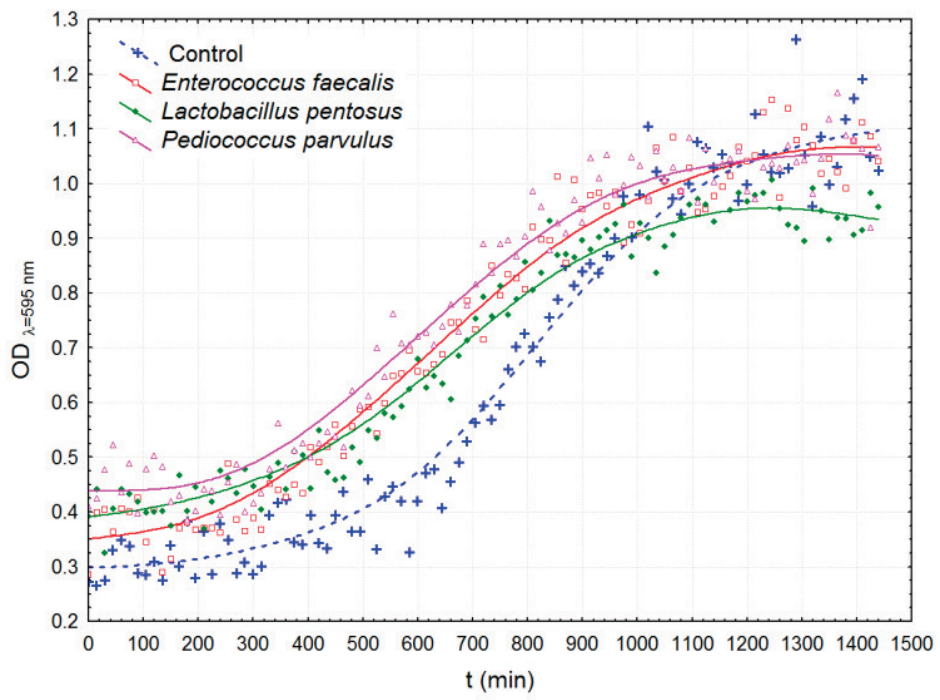

(b)

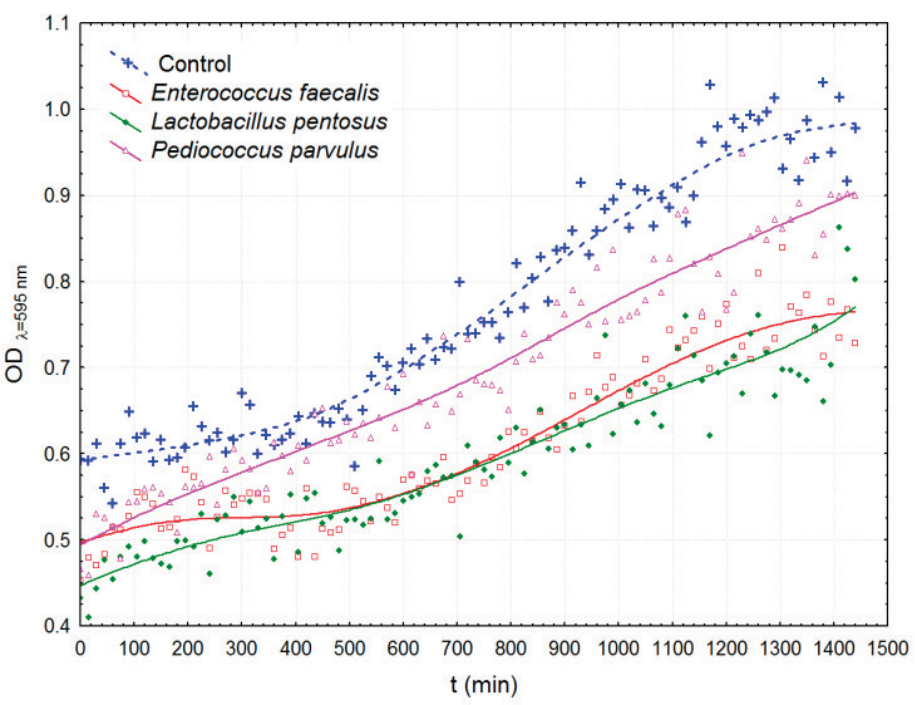

(c)

Figure 3. Growth curves of Saccharomyces cerevisiae 1\% (a), 1.5\% (b), and $2 \%$ (c) in the presence of supernatants of LAB

Tristezza et al. (2016) revealed compatibility between S. cerevisiae and LAB strains during wine making. The positive effect of the yeasts on the growth of 
LAB is attributed to the fact that $S$. cerevisiae favours the growth of lactic acid bacteria (Sieuwerts et al., 2018). Our findings reveal the mirror effects as in this case the supernatant of LAB favoured (or did not inhibit) yeast growth. The practical use of this is the occurrence and co-cultivation of these two microbes in different fermented foods (Ponomarova et al., 2017).

The differences in the mechanism of LAB activity against microbial growth have been attributed to the diversity in the gene expression or molecular structures of tested bacterial strains, which result in different traits and adaptations (Gao et al., 2019).

\section{Conclusions}

Based on these results, the lactic acid bacterial isolates, originating from the different ecology of fermented food products, showed an antibacterial (bacteriostatic) effect against two food-borne pathogen strains. In the case of yeast, they showed compatibility. Lactobacillus pentosus, Enterococcus faecalis, and Pediococcus parvulus exerted an antibacterial bacteriostatic effect on Escherichia coli and Bacillus cereus growth, whereas the Saccharomyces cerevisiae yeast growth was not inhibited, which makes them potential agents for co-culture systems. It can be concluded that lactic acid bacterial strains from diverse fermented food ecosystems possess a bioprotective potential that may contribute to their application as adjunct culture in different cheese and vegetable fermentations.

\section{Acknowledgments}

The authors are grateful to former master's student, Funkenhauzer Bernadett, for the provided help in the experiments.

\section{References}

[1] Baccouri, O. et al., Probiotic potential and safety evaluation of Enterococcus faecalis OB14 and OB15, isolated from traditional Tunisian Testouri cheese and Rigouta, using physiological and genomic analysis. Frontiers in Microbiology, 10. (2019) 881. https://doi.org/ 10.3389/fmicb.2019.00881. 
[2] Belicová, A., Mikulášová, M., Dušinský, R., Probiotic potential and safety properties of Lactobacillus plantarum from Slovak Bryndza cheese. BioMed Research International, 2. (2013).

[3] Ben Said, L., Gaudreau, H., Dallaire, L., Tessier, M., Fliss I., Bioprotective culture: A new generation of food additives for the preservation of food quality and safety. Industrial Biotechnology, 15. 3. (2019) 138147.

[4] EFSA. Opinion of the scientific panel on biological hazards on Bacillus cereus and other Bacillus spp. in foodstuffs. EFSA Journal, 175. (2005) $1-48$.

[5] Gao, Z., Daliri, E. B., Wang, J., Liu, D., Chen, S., Ye, X., Ding, T., Inhibitory effect of lactic acid bacteria on foodborne pathogens: A review. Journal of Food Protection, 82. 3. (2019) 441-453. https://doi.org/ 10.4315/0362-028X.JFP-18-303.

[6] Hanchi, H., Mottawea, W., Sebei, K., Hammami, R., The genus Enterococcus: Between probiotic potential and safety concerns - An update. Frontiers in Microbiology, 9. (2018) 1791. https://doi.org/ 10.3389/fmicb.2018.01791.

[7] Heperkan, D., Daskaya-Dikmen, C., Bayram, B., Evaluation of lactic acid bacterial strains of boza for their exopolysaccharide and enzyme production as a potential adjunct culture. Process Biochemistry, 49. 10. (2014) 1587-1594. https://doi.org/10.1016/j.procbio.2014.06.012.

[8] Laslo, É., György, É., Evaluation of the microbiological quality of some dairy products. Acta Universitatis Sapientiae - Alimentaria, 11. (2018) 27-44. https://doi.org/10.2478/ausal-2018-0002.

[9] Lourens-Hattingh, A., Viljoen, B. C., Growth and survival of a yeast in dairy products. Food Research International, 34. 9. (2001) 791-796.

[10] Lv, X., Miao, L., Ma, H., Bai, F., Lin, Y., Sun, M., Li, J., Purification, characterization and action mechanism of plantaricin JY22, a novel bacteriocin against Bacillus cereus produced by Lactobacillus plantarum JY22 from golden carp intestine. Food Science and Biotechnology, 27. 3. (2017) 695-703. https://doi.org/10.1007/s10068-017-0280-2. 
[11] Montoro, B. P., Benomar, N., Lavilla Lerma, L., Castillo Gutiérrez, S., Gálvez, A., Abriouel, H., Fermented Aloreña table olives as a source of potential probiotic Lactobacillus pentosus strains. Frontiers in Microbiology, 7. (2016) 1583. https://doi.org/10.3389/fmicb.2016.01583.

[12] Motahari, P., Mirdamadi, S., Kianirad, M., Safety evaluation and antimicrobial properties of Lactobacillus pentosus $22 \mathrm{C}$ isolated from traditional yogurt. Food Measure, 11. (2017) 972-978. https://doi.org/ 10.1007/s11694-017-9471-z.

[13] Narbad, A., Wang, G., Lactic acid bacteria and foodborne pathogens. In: Chen, W., Narbad, A., Lactic acid bacteria in foodborne hazards reduction. Singapore, Springer Nature. (2018).

[14] Ponomarova, O. et al., Yeast creates a niche for symbiotic lactic acid bacteria through nitrogen overflow. Cell Systems, 5. 4. (2017) 345-357. https://doi.org/10.1016/j.cels.2017.09.002.

[15] Ruiz Rodríguez, L., Bleckwedel, J., Eugenia Ortiz, M., Pescuma, M., Mozzi, F., Lactic acid bacteria. In: C. Wittmann, J. C. Liao (ed.), Industrial Biotechnology: Microorganisms. Weinheim, Wiley-VCH Verlag GmbH \& Co. KGaA. (2017).

[16] Siedler, S., Balti, R., Neves, A. R., Bioprotective mechanisms of lactic acid bacteria against fungal spoilage of food. Current Opinion in Biotechnology, 56. (2019) 138-146. https://doi.org/10.1016/ j.copbio.2018.11.015.

[17] Siedler, S., Rau, M. H., Bidstrup, S., Vento, J. M., Aunsbjerg, S. D., Bosma, E. F., McNair, L. M., Beisel, C. L., Neves, A. R., Competitive exclusion is a major bioprotective mechanism of lactobacilli against fungal spoilage in fermented milk products. Applied and Environmental Microbiology, 86. (2020) 1-14.

[18] Sieuwerts, S., Bron, P. A., Smid, E. J., Mutually stimulating interactions between lactic acid bacteria and Saccharomyces cerevisiae in sourdough fermentation. LWT - Food Science and Technology, 90. (2018) 201-206.

[19] Silvetti, T., Morandi, S., Brasca, M., Biopreservation potential of Enterococcus faecalis isolated from Italian traditional raw milk cheeses. 
CyTA - Journal of Food, 12. (2014) 210-217. https://doi.org/10.1080/ 19476337.2013 .825327 .

[20] Todorov, S. D., Chikindas, M. C., Lactic acid bacteria bacteriocins and their impact on human health. In: M. A. C. de Albuquerque, A. de Moreno de LeBlanc, J. G. LeBlanc, R. Bedani (eds.), Lactic acid bacteria. A functional approach. Boca Raton: CRC Press. (2020).

[21] Tristezza, M., di Feo, L., Tufariello, M., Grieco, F., Capozzi, V., Spano, G., Mita, G., Simultaneous inoculation of yeasts and lactic acid bacteria: Effects on fermentation dynamics and chemical composition of Negroamaro wine. LWT - Food Science and Technology, 66. (2016) 406-412.

[22] Wade, M. E., Strickland, M. T., Osborne, J. P., Edwards, C. G., Role of Pediococcus in winemaking. Australian Journal of Grape and Wine Research. (2018) https://doi.org/10.1111/ajgw.12366.

[23] Yi, L., Qi, T., Ma, J., Zeng, K., Genome and metabolites analysis reveal insights into control of foodborne pathogens in fresh-cut fruits by Lactobacillus pentosus MS031 isolated from Chinese Sichuan Paocai. Postharvest Biology and Technology, 164. (2020) 111150. https://doi.org/10.1016/j.postharvbio.2020.111150.

[24] Zhang, Q., Lactic acid bacteria and bacteriocins. In: W. Chen, Lactic acid bacteria. Singapore, Springer. (2019).

[25] Zhang, Z., Tao, X., Shah, N. P., Wei, H., Antagonistics against pathogenic Bacillus cereus in milk fermentation by Lactobacillus plantarum ZDY2013 and its anti-adhesion effect on Caco-2 cells against pathogens. Journal of Dairy Science, 99. 4. (2016). 2666-2674. https:// doi.org/10.3168/jds.2015-10587. 